\title{
Pembuatan dan Pengujian Bulk Density, Fluks Magnetik, dan Mikrostruktur pada Hybrid Magnet Berbasis $\mathrm{NdFeB} / \mathrm{BaFe}_{12} \mathrm{O}_{19}$
}

\author{
Djuhana $^{1}$, Muljadi $^{1, *}$, Sunardi $^{1}$, dan Priyo Sardjono ${ }^{2}$ \\ ${ }^{\text {I} P r o g r a m ~ S t u d i ~ T e k n i k ~ M e s i n, ~ U n i v e r s i t a s ~ P a m u l a n g, ~ J l . ~ S u r y a ~ K e n c a n a ~ N o . ~ 1, ~ T a n g e r a n g ~ S e l a t a n, ~ I n d o n e s i a ~}$ \\ ${ }^{2}$ Pusat Penelitian Fisika - LIPI, Gd. 440 Kawasan PUSPIPTEK, Tangerang Selatan, Indonesia
}

E-mail: dosen01545@unpam.ac.id

\begin{abstract}
Abstrak: Telah dilakukan pembuatan hybrid magnet permanen berbasis $\mathrm{NdFeB}$ dengan penambahan $\mathrm{BaFe}_{12} \mathrm{O}_{19}(5,10,15$, dan $20 \%$ wt). Aplikasi hybrid magnet permanen $\mathrm{NdFeB}$ untuk komponen motor dan generator listrik skala kecil. Tujuan penelitian ini adalah untuk mengetahui pengaruhnya penambahan $\mathrm{BaFe}_{12} \mathrm{O}_{19}$ terhadap densitas, fluks magnetik dan mikrostruktur dari hybrid magnet NdFeB. Proses preparasi bahan baku mulai dari pencampuran serbuk NdFeB tipe MQP-B+ dengan $\mathrm{BaFe}_{12} \mathrm{O}_{19}$, digerus dan dicampur bahan perekat Epoxy Resin sebanyak $6 \%$ wt dan dicetak dengan gaya 8 tonf sehingga membentuk pellet dengan diameter 18,5 dan tebal 4,3 $\mathrm{mm}$. Sampel yang telah dicetak kemudian dikeringkan pada kondisi vacuum ( \pm 15 mbar) dengan temperatur $80^{\circ} \mathrm{C}$ ditahan selama 1 jam. Karakterisasi yang dilakukan meliputi pengukuran bulk density, microstructurer menggunakan Optical Microscope dan sifat magnet dengan menggunakan Gaussmeter. Dari hasil karakterisasi secara keseluruhan diperoleh kondisi optimum pada komposisi hybrid magnet $\mathrm{NdFeB}$ adalah $95 \% \mathrm{NdFeB}, 5 \%$ wt $\mathrm{BaFe}_{12} \mathrm{O}_{19}$. Sifat-sifat hybrid magnet $\mathrm{NdFeB}$ tersebut adalah bulk density $=4,469 \mathrm{~g} / \mathrm{cm}^{3}$, Fluks magnetik $=1029,85$ Gauss, ukuran bulir (grain size) sekitar 4,1 $-5,2 \mu \mathrm{m}$.
\end{abstract}

Kata kunci: $\mathrm{BaFe}_{12} \mathrm{O}_{19}, \mathrm{NdFeB}$, Epoxy Resin, Densitas, Fluks Magnetik, Mikrostruktur, Hybrid Magnet

\begin{abstract}
NdFeB-based permanent hybrid magnets have been made with the addition of $\mathrm{BaFe}_{12} \mathrm{O}_{19}(5,10,15$, and 20 wt\%). The applications of $\mathrm{NdFeB}$ permanent magnet hybrid are for component of motor and small-scale electrical generators. The purpose of this research is to know the influence of the addition of BaFe12O19 to density, magnetic flux and microstructure of $\mathrm{NdFeB}$ hybrid magnet. Preparation process started by mixing $\mathrm{NdFeB}(\mathrm{MQP}-\mathrm{B}+)$ powder with $\mathrm{BaFe}_{12} \mathrm{O}_{19}$, then mixed with addhesive Exopy Resin $6 \%$ wt and compacted with pressure 8 tonf to form a pellet with diameter of 18,5 and thickness 4,3 mm. Samples which have been pressed then dryed using Under Vacuum Dryer with heating temperature $80^{\circ} \mathrm{C}$ and pressure 15 mbar held for 1 hour. The characterizations was conducted on the physical properties, such as density by using dimension method, microstructure analysis using OM, and magnetic properties with gaussmeter. The best result over all samples is hybrid magnet $\mathrm{NdFeB}$ with compositions of $95 \% \mathrm{NdFeB}, 5 \%$ wt BaFe ${ }_{12} \mathrm{O}_{19}$. Properties of hybrid magnet $\mathrm{NdFeB}$ of this compositions are bulk density value $=4,469 \mathrm{~g} / \mathrm{cm}^{3}$, magnetic flux value $=1029,85$ Gauss, mean particle size based of optical microscope in range 4,1-5,2 $\mu \mathrm{m}$.
\end{abstract}

Keywords: $\mathrm{BaFe}_{12} \mathrm{O}_{19}, \mathrm{NdFeB}$, Epoxy Resin, Density, Flux Magnetic, Microstructure, Hybrid Magnet

\section{PENDAHULUAN}

Magnet menjadi bagian yang tidak terpisahkan dari kehidupan manusia masa kini. Mulai dari peralatan listrik sampai dengan peralatan nonlistrik memanfaatkan magnet permanen, contohnya loudspekaer, meteran air, KWH-meter, ricecooker, transformer dan generator. Karakterisitik bahan-bahan magnetik ditentukan oleh besaran-besaran magnetik seperti suseptibilitas, magnetisasi remanen, magnetisasi saturasi dan medan koersivitas [1].

Perkembangan magnet permanen saat ini sangat difokuskan untuk magnet permanen energi tinggi. Salah satu bahan magnet permanen yang dapat menghasilkan energi tinggi tersebut adalah dari jenis $\mathrm{Re}-\mathrm{Fe}-\mathrm{B} \quad(\mathrm{Re}=$ 
Nd, Pr)[2]. Bahkan magnet permanen berbasis Nd-Fe-B telah menghasilkan energi produk mencapai 50 MGOe. Magnet permanen berjenis Re-Fe-B ini terbuat dari paduan logam tanah jarang berjenis Neodymium atau Praseodymium, logam Besi, dan Boron dengan fasa magnet $\mathrm{Nd}_{2} \mathrm{Fe}_{14} \mathrm{~B}$ atau $\operatorname{Pr}_{2} \mathrm{Fe}_{14} \mathrm{~B}$ yang memiliki struktur kristal tetragonal [3]. Kelebihan lain dari magnet permanen berbasis Re-Fe-B ini adalah memiliki Induksi magnet saturasi yang tinggi mencapai1,6T atau16 kG, dengan induksi remanensi tertinggi saat ini mencapai1,53T atau 15,3 kG dalam bentuk sintered magnet [4]. Karena sifat magnetik yang sangat baik, bahan magnetik logam tanah jarang seperti NdFeB banyak digunakan untuk berbagai aplikasi seperti sensor dan motor elektrik performa tinggi. Namun kelemahan $\mathrm{NdFeB}$ adalah sifat termalnya yang kurang baik sehingga tidak dapat digunakan pada suhu yang tinggi [5]. Magnet permanen basis ferrit seperti barium ferrite dan stronsium ferrite merupakan magnet permanen komersial jenis keramik. Magnet keramik dibuat dari bubuk magnet hasil kalsinasi yang telah dihaluskan, dicetak, dan disinter. Karakteristik magnet keramik sangat bergantung dari karakteristik mikrostrukturnya. Barium Ferrite telah menjadi rujukan yang menarik dalam dunia material magnet dan telah dipakai secara luas sebagai magnet permanen. Hal tersebut disebabkan magnetocrystalline anisotrophy yang cukup besar $\left(1.07 \mathrm{x} 105 \mathrm{erg} / \mathrm{cm}^{3}\right.$ pada suhu $\left.77 \mathrm{~K}\right)$ dan temperatur Curie yang tinggi $\left(450^{\circ} \mathrm{C}\right)$, dengan magnetisasi saturarsi yang relatif besar $(96,27 \mathrm{emu} / \mathrm{g})$, kestabilan kimia yang baik dan tahan korosi [6]. Magnet barium ferit mempunyai medan koersivitas yang tinggi dan tahan terhadap korosi. Meskipun karakteristik energinya lebih rendah dibandingkan dengan magnet keras lainnya seperti magnet neodymium iron boron $(\mathrm{NdFeB})$, samarium-cobalt $(\mathrm{Sm}-\mathrm{Co})$, dan alnico (Al-Ni-Co), tetapi magnet keras ferit masih banyak digunakan untuk aplikasi magnet permanen karena bahannya yang melimpah dan murah [7]. Magnet yang dihasilkan dari proses pencampuran $\mathrm{NdFeB}$ dengan bahan ferit disebut Hybrid Magnet, yang memiliki sifat termal yang lebih baik dari pada $\mathrm{NdFeB}$ yang murni dan dapat bekerja pada temperatur yang lebih tinggi (120 $200^{\circ} \mathrm{C}$ ) $[8,9]$. Pencampuran $\mathrm{NdFeB}$ dengan Barium Ferrite dan serbuk besi dapat memberikan keuntungan yaitu menghasilkan magnet yang berdampak menurunkan biaya produksi waluapun sifat magentiknya terjadi penurunan [9]. Karena material $\mathrm{BaFe}_{12} \mathrm{O}_{19}$ memiliki sifat megantik yang lebih rendah dari material paduan $\mathrm{NdFeB}$, tetapi kelebihan dari $\mathrm{BaFe}_{12} \mathrm{O}_{19}$ adalah murah dan lebih stabil terhadap kondisi atmosfer.

Pada penelitian ini akan dilakukan pembuatan hybrid magnet $\mathrm{NdFeB}$ menggunakan bahan baku serbuk $\mathrm{NdFeB}$ tipe MQP-B+ dengan penambahan komposisi serbuk $\mathrm{BaFe}_{12} \mathrm{O}_{19}$ komersil. Tujuan penelitian ini adalah untuk mengetahui pengaruhnya terhadap densitas, fluks magnetik dan mikrostruktur dari hybrid magnet NdFeB.

\section{METODOLOGI}

Bahan-bahan yang digunakan yaitu serbuk $\mathrm{NdFeB}$ tipe $\mathrm{MQP}-\mathrm{B}+$, Barium Hexaferrite $\left(\mathrm{BaFe}_{12} \mathrm{O}_{19}\right)$, Epoxy Resin, dan Hardener Resin. Diagram alir preparasi sampel ditunjukan pada Gambar 1. Prosedur yang dilakukan dalam pembuatan hybrid magnet $\mathrm{NdFeB}$ dengan variasi komposisi $\mathrm{BaFe}_{12} \mathrm{O}_{19}$ dimulai dengan proses mixing, pembuatan sampel uji, analisa bulk densitas, fluks magnetik dan mikrostruktur dengan menggunakan Optical Microscope (OM).

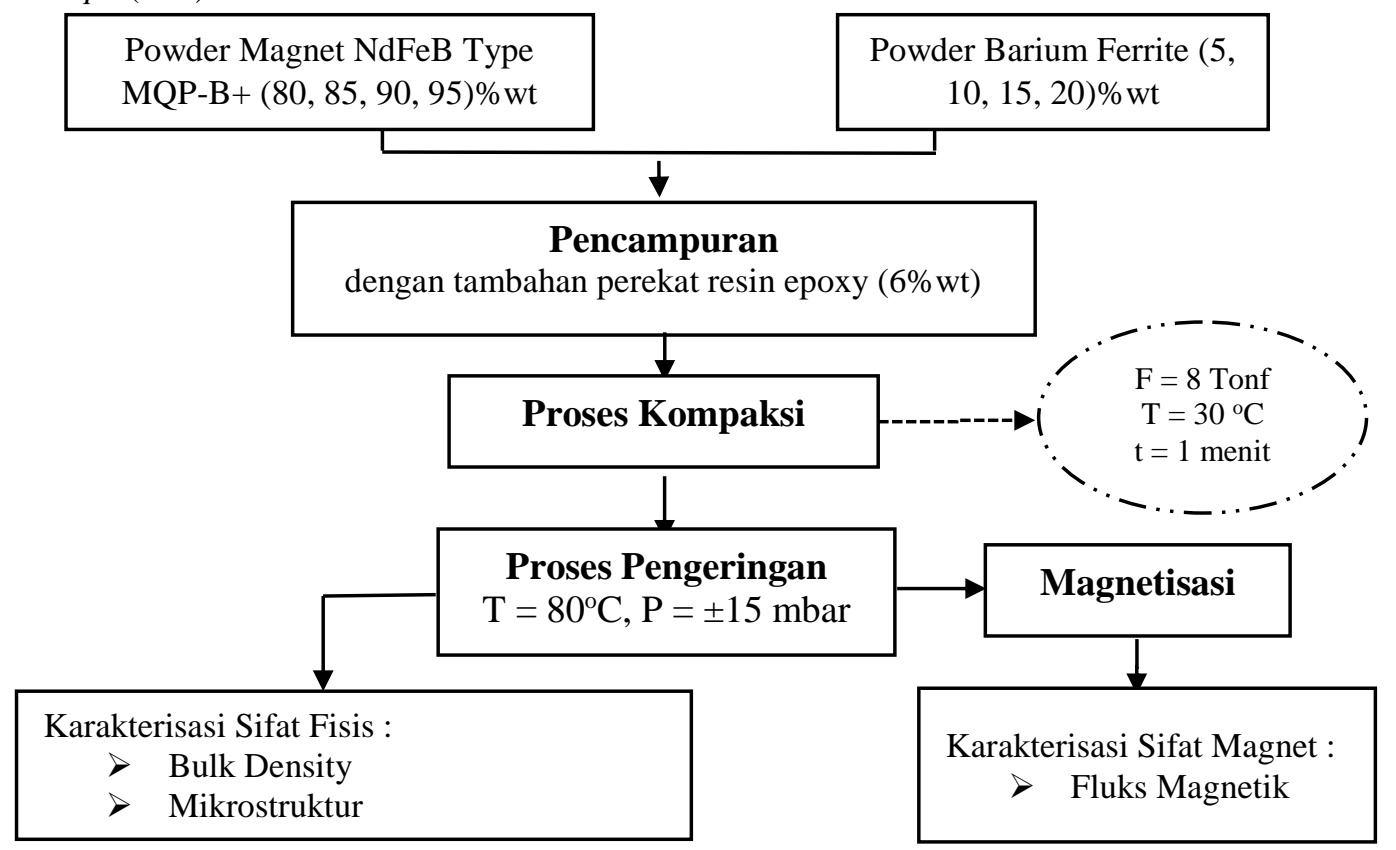

Gambar 1. Diagram Alir preparasi sampel hybrid magnet berbasis $\mathrm{NdFeB} / \mathrm{BaFe}_{12} \mathrm{O}_{19}$. 
Untuk membuat hybrid magnet $\mathrm{NdFeB} / \mathrm{BaFe}_{12} \mathrm{O}_{19}$ disediakan bahan baku yang dibutuhkan yaitu serbuk $\mathrm{NdFeB}$ tipe MQP-B+, serbuk Barium Hexaferrite $\mathrm{BaFe}_{12} \mathrm{O}_{19}$. Bahan baku tersebut kemudian dicampur dengan menggunakan Hand Mortar. Serbuk ditimbang dengan perbandingan 95:5 , 90:10, 85:15 dan 80:20. Masingmasing serbuk yang telah ditimbang dengan perbandingan yang telah ditentukan dicampur di Hand Mortar hingga homogen. Serbuk yang telah homogen dipindahkan ke Beaker Glass ukuran $50 \mathrm{ml}$ dan ditambahkan 6 $\%$ wt Resin Epoxy kemudian dibuat homogen kembali. Menambahkan Hardener Resin sebanyak 4 tetes kemudian diaduk kembali. Setelah serbuk dicampur, kemudian dicetak dengan alat Carver Hydraulic Press dengan gaya 8 tonf dan ditahan selama 1 menit. Setelah sampel dikompaksi. Selanjutnya sampel di keringkan pada kondisi vacuum ( \pm 15 mbar) pada suhu $80^{\circ} \mathrm{C}$ selama 1 jam. Setelah dilakukan pengeringan, proses selanjutnya adalah magnetisasi pada sampel hybrid magnet $\mathrm{NdFeB} / \mathrm{BaFe}_{12} \mathrm{O}_{19}$ dengan menggunakan Physic $D r$. Steingroever GmbH Impulse Magnetizer K-Series. Kemudian dilakukan karakterisasi densitas, fluks magnetik dan mikrostruktur dari hybrid magnet $\mathrm{NdFeB} / \mathrm{BaFe}_{12} \mathrm{O}_{19}$.

\section{HASIL DAN PEMBAHASAN}

Pengukuran densitas untuk hybrid magnet $\mathrm{NdFeB} / \mathrm{BaFe}_{12} \mathrm{O}_{19}$ dilakukan dengan menggunakan metode pengukuran dimensi volume. Hasil pengukuran densitas hybrid magnet $\mathrm{NdFeB}$ diperlihatkan pada Gambar 2 . Gambar 2 menunjukan bahwa nilai densitas menurun seiring dengan penambahan aditif $\mathrm{BaFe}_{12} \mathrm{O}_{19}$. Nilai densitas maksimum diperoleh pada penambahan $5 \% \mathrm{wt} \mathrm{BaFe}_{12} \mathrm{O}_{19}$ dengan nilai $4,47 \mathrm{~g} / \mathrm{cm}^{3}$. Adanya penambahan komposisi $\mathrm{BaFe}_{12} \mathrm{O}_{19}$ menyebabkan nilai densitas cenderung menurun, hal ini disebabkan oleh nilai densitas $\mathrm{BaFe}_{12} \mathrm{O}_{19}\left(3,45 \mathrm{~g} / \mathrm{cm}^{3}\right)$ yang lebih kecil dari nilai densitas bonded $\mathrm{NdFeB}\left(5,05 \mathrm{~g} / \mathrm{cm}^{3}\right)$.

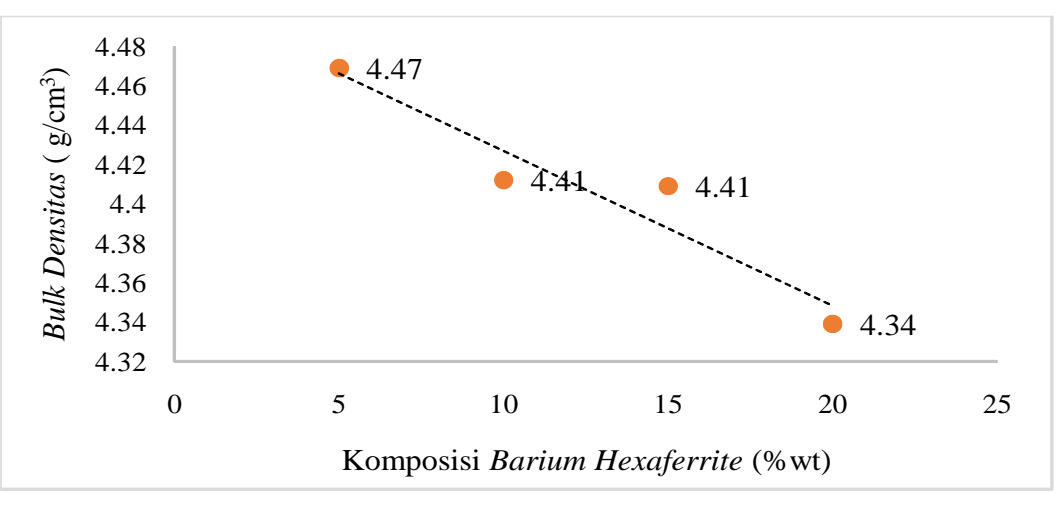

Gambar 2. Grafik hubungan densitas pada sampel hybrid magnet berbasis $\mathrm{NdFeB} / \mathrm{BaFe}_{12} \mathrm{O}_{19}$ dengan variasi komposisi $\mathrm{BaFe}_{12} \mathrm{O}_{19}$.

Pengamatan mikrostruktur dilakukan dengan mengamati foto morfologi permukaan magnet dan penentuan ukuran partikel dengan menggunakan peralatan Optical Microscope (OM). Hasil pengamatan dengan OM ditunjukkan pada Gambar 3.

Pengamatan OM dilakukan pada 4 sampel dengan variasi komposisi Barium Hexaferrite 5, 10, 15 dan 20 $\%$ wt. Dari gambar foto OM dapat dilihat bahwa yang berwarna abu-abu merupakan partikel NdFeB, sedangkan bewarna putih merupakan partikel Barium Hexaferrite $\left(\mathrm{BaFe}_{12} \mathrm{O}_{19}\right)$. Karena bentuk sampel berbentuk pelet maka ukuran bulir (grain size) di ukur berdasarkan pengamatan menggunakan optical microscope. Berdasarkan hasil Optical Microscope, dapat ditentukan ukuran bulir rata-rata dari bahan penyusun sampel dengan variasi komposisi Barium Hexaferrite yang ditunjukkan pada Tabel 1. 


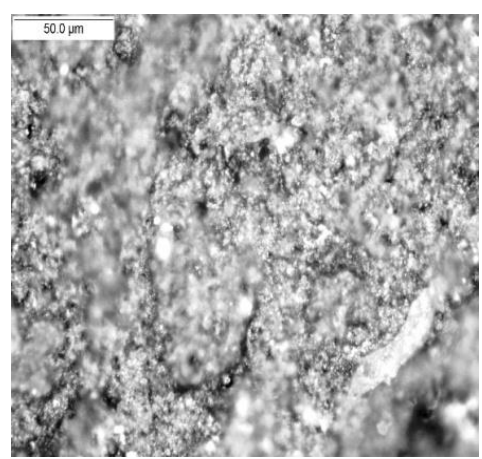

(a)

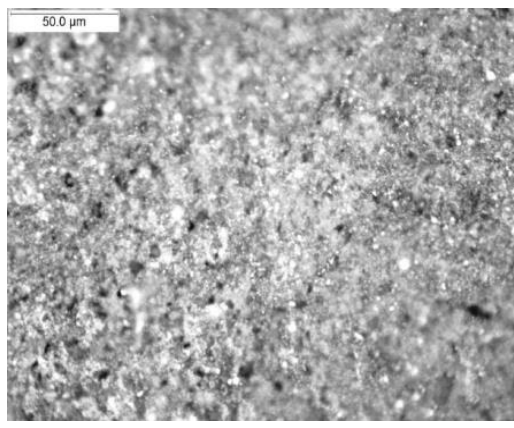

(c)

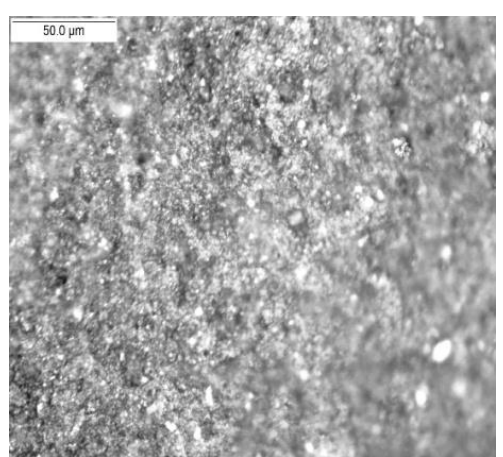

(b)

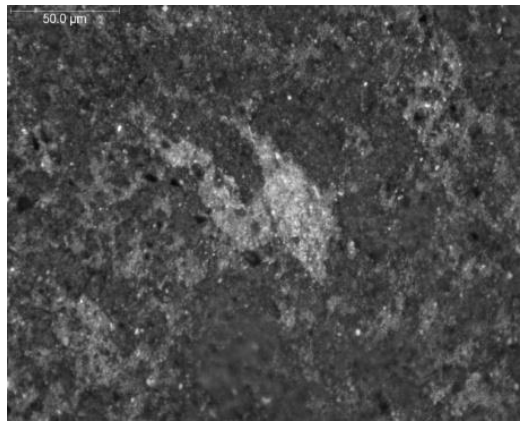

(d)

Gambar 3. Foto morfologi permukaan hybrid magnet berbasis $\mathrm{NdFeB} / \mathrm{BaFe}_{12} \mathrm{O}_{19}$ dengan variasi komposisi $\mathrm{BaFe}_{12} \mathrm{O}_{19}$ (a) 5 $\%$ wt (b) $10 \%$ wt (c) $15 \%$ wt dan (d) $20 \%$ wt pada pembesaran 40x.

Tabel 1. Data hasil pengujian densitas dari hybrid magnet $\mathrm{NdFeB}$ dengan variasi komposisi $\mathrm{BaFe}_{12} \mathrm{O}_{19}$

\begin{tabular}{ccc}
\hline $\begin{array}{c}\text { Variasi Komposisi } \\
\mathrm{BaFe}_{12} \mathrm{O}_{19}(\% \text { wt })\end{array}$ & Ukuran bulir NdFeB $(\mu \mathrm{m})$ & Ukuran bulir $\mathrm{BaFe}_{12} \mathrm{O}_{19}(\mu \mathrm{m})$ \\
\hline 5 & 4,78 & 5,15 \\
10 & 4,25 & 5,15 \\
15 & 4,10 & 4,18 \\
20 & 4,48 & 5,22 \\
\hline
\end{tabular}

Berdasarkan dari hasil di Tabel 1 terlihat bahwa ukuran bulir di semua komposisi untuk NdFeB adalah sekitar 4,1 - 4,7 $\mu \mathrm{m}$, kemungkinan hal ini distribusi ukuran bulirnya di bahan baku awalnya tidak merata, begitu pula untuk ukuran bulir $\mathrm{BaFe}_{12} \mathrm{O}_{19}$ juga bervariasi dari 4,1 - 5,2 $\mu \mathrm{m}$, hal ini juga kemungkinan distribusi ukuran bulir dari bahan awalnya tidak homogen. Akan tetapi ukuran buir NdFeB sedikit lebih besar dibandingkan dengan ukuran bulir $\mathrm{BaFe}_{12} \mathrm{O}_{19}$. Berdasarkan hasil observasi pada OM, yang seperti terlihat pada Gambar 3 yaitu pada Gambar 3 (a) hybrid magnet dengan komposisi $5 \%$ wt $\mathrm{BaFe}_{12} \mathrm{O}_{19}$ terlihat ukuran bulir $\mathrm{NdFeB}$ dan partikel $\mathrm{BaFe}_{12} \mathrm{O}_{19}$ tidak homogen bentuk bulirnya tapi kedua partikel telah terdistribusi rata. Selanjutnya untuk Gambar 3 (b), (c) dan (d) menunjukan pola yang serupa dengan Gambar 3 (a). Dari hasil observasi dengan OM, perekat epoxy resin berada diantara bulir-bulir akan tetapi tidak terlihat jelas pada foto OM. Kemungkinan akan terlihat jelas bila diamati dengan Scanning Electron Microscope.

Untuk mengetahui kuat medan magnet dari sampel hybrid magnet NdFeB maka dilakukan pengukuran dengan menggunakan Gaussmeter. Hasil pengukuran Gaussmeter (kuat medan magnet) ditunjukkan pada Tabel 2.

Tabel 2. Data pngujian kuat medan magnet $\mathrm{NdFeB}$ dengan Variasi komposisi $\mathrm{BaFe}_{12} \mathrm{O}_{19}$

\begin{tabular}{cccc}
\hline $\begin{array}{c}\text { Komposisi } \\
\text { Barium Hexaferrite (\%wt) }\end{array}$ & $\begin{array}{c}\text { Fluks Magnetik } \\
\text { Kutub Positif (Gauss) }\end{array}$ & $\begin{array}{c}\text { Fluks Magnetik Kutub } \\
\text { Negatif (Gauss) }\end{array}$ & $\begin{array}{c}\text { Fluks Magnetik Rata- } \\
\text { rata (Gauss) }\end{array}$ \\
\hline 5 & 1064 & 996 & 1030 \\
10 & 991 & 991 & 991 \\
15 & 858 & 856 & 857 \\
20 & 843 & 716 & 780 \\
\hline
\end{tabular}


Berdasarkan hasil pengukuran nilai kuat medan magnet pada Tabel 2 terlihat bahwa pada sampel dengan penambahan komposisi 5 \% wt Barium Hexaferrite diperoleh nilai fluks magnetik tertinggi yaitu 1030 gauss. Semakin bertambahnya komposisi Barium Hexaferrite mengurangi nilai fluks magnetik sampel karena sifat magnet Barium Hexaferrite lebih rendah dari bonded $\mathrm{NdFeB}$ yaitu sekitar 1125 Gauss sehingga menurunkan sifat magnetiknya.

\section{KESIMPULAN}

Berdasarkan penelitian diatas diperoleh kesimpulan telah berhasil dibuat hybrid bonded magnet berbasis $\mathrm{NdFeB} / \mathrm{BaFe}_{12} \mathrm{O}_{19}$. Kondisi optimum diperoleh pada pembuatan hybrid bonded magnet dengan komposisi $95 \%$ $\mathrm{NdFeB}$ dan $5 \%$ wt $\mathrm{BaFe}_{12} \mathrm{O}_{19}$ yang memiliki sifat-sifat : Bulk Density $=4,47 \mathrm{~g} / \mathrm{cm}^{3}$. Ukuran partikel rata-rata dari hasil pengukuran mikrostruktur adalah berkisar 4,1 - 5,2 $\mu \mathrm{m}$. Fluks Magnetik = 1030 Gauss. Penurunan sifat fisis maupun magnet dari $\mathrm{NdFeB}$ yang sebanding dengan penambahan $\mathrm{BaFe}_{12} \mathrm{O}_{19}$.

\section{DAFTAR PUSTAKA}

[1] Hayati R, Budiman A dan Puryanti D (2016) Jurnal Fisika Unand 5187

[2] Drak M dan Dobrzański L A 2007 Journal of Achievements in Materials and Manufacturing Engineering 24

[3] Brown D, Ma B M dan Chen Z 2002 Journal of Magnetism and Magnetic Materials 248432

[4] Kurniawan C, Yuswita A dan Muljadi 2013 Pembuatan Rigid Bonded Magnet Berbasis Pr-Fe-B untuk Komponen Generator Listrik Mini Prosiding Seminar Nasional Kimia Terapan Indonesia

[5] Ferreira B 2011 Use of Strontium Ferrite Powder in the Production of Hybrid Rare-Earh Bonded Magnets (Sao Paulo: Instituto de Pesquisas Energiticas Nucleares)

[6] Ovalioglu H 2010 Magnetic Properties of Nano-Crystalline Barium Ferrite Synthesized by Different Synthesis Route (Turkey: Uludag University)

[7] Irasari P dan Idayanti N 2009 Jurnal Sains Material Indonesia 1138

[8] Plusa D, Dospial M, Slusarek B, Kotlarczyk U dan Mydlarz T 2008 Rev. Adv. Mater. Sci. 18 P.541

[9] Kokabi M, Arabgol F dan Manteghian M 2005 Iranian Polymer Journal 1471 